\title{
LAS IMÁGENES DE JERÓNIMO NADAL Y UN RETABLO NOVOHISPANO
}

\author{
Luisa Elena Alcalá
}

Los grabados de las Imágenes de la historia evangélica del Padre Jerónimo Nadal como modelo pictórico en la pintura española han sido el objeto de varias publicaciones recientes. Dos trabajos que dan a conocer su uso por artistas españoles son "Las Evangelicae Historiae Imagenes del padre Nadal como fuente de inspiración para un ciclo de pinturas del eremitorio de l'Avellá (Cati)", de Fernando Marín Rosas, y "Jerome Nadal and Francisco Pacheco: A Print and a Verbal Source for Zurbarán's Circumcision (1639)", de Eugene R. Cunnar. ${ }^{1}$ De los 153 grabados del libro de Nadal, parece ser que el de la Circuncisión fue uno de los que se utilizó con mayor frecuencia como modelo de obras pictóricas. En su artículo, Cunnar reconoce la influencia de ese grabado en la obra de Zurbarán. Lo que ahora se descubre es la influencia de este grabado en la Nueva España, y concretamente, en uno de los óleos del retablo de la Virgen de los Dolores que proviene de la hacienda jesuita de Santa Lucía, en las cercanías de la ciudad de México. ${ }^{2}$

Este retablo salomónico es obra de artistas desconocidos y ha sido fechado aproximadamente en el año 1690 por Clara Bargellini. ${ }^{3}$ Consta de cinco grandes telas, repartidas en dos cuerpos, y de dos telas de dimensiones más pequeñas en la predela. ${ }^{4}$ Cada óleo representa uno de los siete dolores de la Virgen, comenzando con la Presentación del Niño Jesús al Templo, en la predela de la izquierda; es éste el que constituye el tema del presente estudio. La manera en que nuestro pintor utilizó el grabado de la Circunci-

${ }^{1}$ Ambos artículos se encuentran en el Boletin del Museo e Instituto Camón Aznar: XXXIX (1990), 87-101 y XXXIII (1988), 105-112.

${ }^{2}$ Agradezco la ayuda que la Profra. Clara Bargellini (UNAM) me brindó siendo su alumna en el Institute of Fine Arts (NYU) de Nueva York La parte inferior del retablo fue traída a Nueva York para la exposición Mexico: Splendors of Thirty Centuries (Metropolitan Museum of Art, New York, 1990), lo cual me permitió trabajar sobre él con detenimicnto. En la actualidad este retablo pertenece al Centro Cultural Arte Contemporáneo.

${ }^{3}$ Bargellini, "Lower portion of a Retablo", Mexico: Splendors of Thirty Centuries, Metropolitan Museum of Art, 1990, p. 339

${ }^{4}$ En su estado actual, sólo quedan seis de las pinturas originales; la del centro del segundo nivel en algún momento fue desplazada por un cuadro que representa a la mártir Santa Lucía. En su lugar, originalmente se encontraba la representación de la Crucifixión, lo cual era de esperar en un ciclo de los dolores de la Virgen Bargellini, op cit., 339-342. 
sión de las Imágenes en esta tela plantea ciertos problemas iconográficos y dogmáticos por ser combinada la Circuncisión con la escena de la Presentación. ${ }^{5}$ Sus peculiaridades nos llevaran a investigar el contexto jesuítico en el cual se confeccionó el retablo.

La obra Imágenes de la historia evangélica fue por primera vez publicada en Amberes en el año 1593 por la imprenta de Plantino; luego, en 1606, y repetidas veces durante el siglo xvII. ${ }^{6}$ Esta obra surgió como resultado de un proyecto iniciado en 1562 por San Francisco de Borja, tercer general de la Compañía, quien no llegó a completar la obra durante su vida. Pasó después a manos del Padre Nadal, quien ya había trabajado con Borja en la preparación del libro. El objetivo era que este libro, esencialmente una colección de imágenes acompañadas de unas anotaciones, se utilizara para la enseñanza y educación de los novicios. En 1575 Nadal había terminado las notas y meditaciones que ilustrarían las correspondientes imágenes. Tras su muerte en 1580, el proyecto quedó en manos de su amigo y secretario, el P. Diego Jiménez, a quien se le encomendó que encargará a varios artistas la confección de los grabados.

En Imágenes tuvo gran éxito desde muy temprano, siendo una de las publicaciones de Plantino más divulgadas en España y consiguientemente en sus colonias del Nuevo Mundo. Los misioneros jesuitas aprovecharon el potencial instructivo de esta obra en las colonias. En 1593, al pedir subvenciones al Papa Clemente XVIII para cubrir los gastos de grabación, el P. Pablo Hoffeo señaló la enorme demanda de estos grabados no sólo en Europa sino, como nos dice Rodríguez de Ceballos, en "unas y otras Indias, ya que gracias a las estampas era más fácil hacer comprender a los nuevos cristianos los misterios de la fe". ${ }^{7} \mathrm{Al}$ ser un libro sin texto, en los primeros años de colonización las imágenes podían comunicar con más facilidad las enseñanzas del evangelio a los indígenas, poco instruidos aún en la lengua española.

El uso del grabado en el retablo de Santa Lucía, pasado un siglo desde la primera publicación de las Imágenes, confirma que la obra de Nadal seguía siendo importante en la colonia incluso a finales del siglo xvir. Pero mientras que en la época de conquista y colonización el libro se había utilizado para

\footnotetext{
${ }^{5}$ Sobre el uso de grabados en la pintura de la colonia, se debe ver Jorge Alber to Manrique, "La estampa como fuente del arte en la Nueva España", Anales, núm. 50 (México, 1982), pp. 5560, y Marcus Burke, "Print Sources in Mexican Painting", Spain and New Spain: Colonial Arts in their European Context, Art Museum of South Texas (Texas, 1979), pp. 30-36.

${ }^{6}$ Rodríguez G. de Ceballos, "Las Imágenes de la historia evangélica del P. Jerónimo Nadal en el marco del jesuitismo y la contrarreforma", Imágenes de la historia evangélica (1593). Barcelona, El Albir, 1975, pp. 7-15.

${ }^{7}$ Ibid, pp. 14. En su estudio introductorio, este autor da varios ejemplos de la popularidad de la obra de Nadal en las misiones jesuíticas.
} 
facilitar la conversión, en el siglo xvi fue usado por los artistas de la colonia para la creación de sus obras. ${ }^{8}$

La composición de la predela de la izquierda de nuestro retablo está basada en el grabado de la Circuncisión de Jerónimo Wierix que forma parte de las Imágenes de Nadal. En ambas obras vemos un grupo de espectadores, entre ellos la Virgen María y San José, situados alrededor de Simeón, el cual sostiene al niño Jesús sobre el altar mientras un ayudante realiza la circuncisión. No sólo la distribución de las figuras es idéntica a la del grabado, sino también muchos otros detalles: por ejemplo, los gestos nerviosos de María: sus manos aparecen elevadas en ademán de preocupación por el dolor del Niño Jesús, quien en ambas obras, además, está envuelto en ropas blancas y mira en dirección a su madre.

Debemos recalcar que al usar el grabado de Wierix, el pintor de esta tela efectuó algunos cambios de tipo estilístico. Por ejemplo, suprimió los escalónes que aparecen en el primer plano del grabado. También se observa que el paisaje al extremo derecho del grabado ha sido sustituido en la tela por un interior arquitectónico, eliminando de esta manera las escenas secundarias que ocupan el fondo del grabado. Al simplificar así la composición, el pintor de la predela dirige la atención del espectador hacia la escena central.

El uso del grabado de Wierix en un contexto dedicado a la Virgen de los Dolores acarrea inevitablemente ciertos cambios de tipo iconográfico. El más evidente es que en la predela se ha añadido el atributo esencial de la Dolorosa, la espada que atraviesa su pecho. Notamos asimismo que la bandeja con jarrones y vasijas que lleva el criadito en el grabado ha sido sustituida por la ofrenda de dos pichones. Aunque a primera vista esto pueda parecer un cambio insignificante, resulta ser fundamental para la iconografía de nuestro retablo: el detalle de los pichones introduce el tema de la Presentación al Templo que queda combinado con el de la Circuncisión.

La Presentación es el primer dolor de la Virgen: las palabras proféticas pronunciadas por Simeón en ese momento dieron lugar en la tardía Edad Media al culto mariano de la Dolorosa. ${ }^{9}$ Simeón recibe en brazos al Niño y le dice a la Virgen: "Puesto está para caída y levantamiento de muchos en

${ }^{8}$ Aunque no cabe duda de que el grabado de Wierix fue el modelo de la predela de la Presentación-Circuncisión del retablo de Santa Lucía, debemos subrayar que, al parecer, no se usó ningún otro grabado de Imágenes para crear el resto de los óleos, aunque siempre cabe la posibilidad de que una u otra figura se tomara de sus ciento cincuenta y tres grabados.

${ }^{9}$ Véase para un resumen de la historia del culto a la Virgen de los Dolores: Gustavo Curiel, "Las pinturas de nuestra Señora de los Dolores y nuestra Señora de la Piedad en la obra de Juan Correa", en Juan Correa, su vida y su obra, vol. 1 . 
Israel, y para blanco de contradicción; y para que se descubran los pensamientos de muchos corazones, una espada atravesará tu alma" (Luc. 2, 3435). Además de ser ésta la base bíblica de la devoción a la Virgen de los Dolores, determina también la iconografía pictórica que la representa. La espada que atraviesa el corazón de María se convierte en el atributo invariable de la Virgen de los Dolores, presente en nuestra predela al igual que en las otras telas del retablo.

Es posible identificar la escena de la Presentación en la predela por la presencia de los dos pichones que el criadito lleva en su cesta: son el símbolo tradicional de la Presentación. La misma narración evangélica menciona que en ese momento se cumplió la norma de la ley (Lev. 12,8) de ofrecer "en sacrificio un par de tórtolas o dos pichones" (Luc. 2, 24). ${ }^{10}$ Sin embargo, la acción central de la predela no es la de la Presentación, sino la de la Circuncisión.

Queda visto así que, desde el punto de vista iconográfico, la escena de la predela representa simultáneamente dos sucesos de la vida del Niño Jesús: la Presentación y la Circuncisión. La Presentación del recién nacido se celebra litúrgicamente el 2 de febrero, cuarenta días después del nacimiento conforme a la leyjudía, en tanto que la Circuncisión hubo de tener lugar pocos días después del nacimiento; de hecho, su celebración litúrgica es el 1 de enero. Ya que la integración de las dos escenas en una sola no se adhiere a las leyes judías ni a su conmemoración por la Iglesia, es necesario investigar si tiene algún antecedente en la tradición pictórica de Nueva España.

En la época en que fue ejecutada esta obra, Juan Correa era uno de los pintores que dominaban la producción de retablos en la ciudad de México y en sus cercanías. Nos referimos a este maestro en concreto ya que se cree que Correa ejerció una gran influencia sobre nuestro pintor, y que además es muy posible que el retablo de Santa Lucía se haya confeccionado en la ciudad de México. ${ }^{11}$

En su estudio sobre la Virgen de los Dolores, Gustavo Curiel apunta que Correa, junto con su contemporáneo Cristóbal Villalpando, estableció una fórmula pictórica para la representación de la Dolorosa ${ }^{12}$ Sus obras se basaban en la iconografía de la Piedad: la Virgen aparece sentada al pie de la cruz rodeada de ángeles pasionarios. De este tipo es, por ejemplo, la "Dolorosa con ángeles de la Pasión", de la catedral de San Cristóbal de las

\footnotetext{
${ }^{10}$ Los pichones son en realidad el ofrecimiento de la Virgen, ya que marcan su Purificación, que coincide con la Presentación del Niño al Templo. Louis Réau, Iconographie de l'art chrétien, vol. 2, Paris, Presses Universitaires de France, 1957, pp . 261-262.

${ }^{11}$ Clara Bargellini confirma que, aunque el r etablo sea obra de pintor no identificado, su estilo se aproxima al de Juan Correa. Bargellini, op cit, p. 340.

${ }^{12}$ Guriel, op. cit.
} 


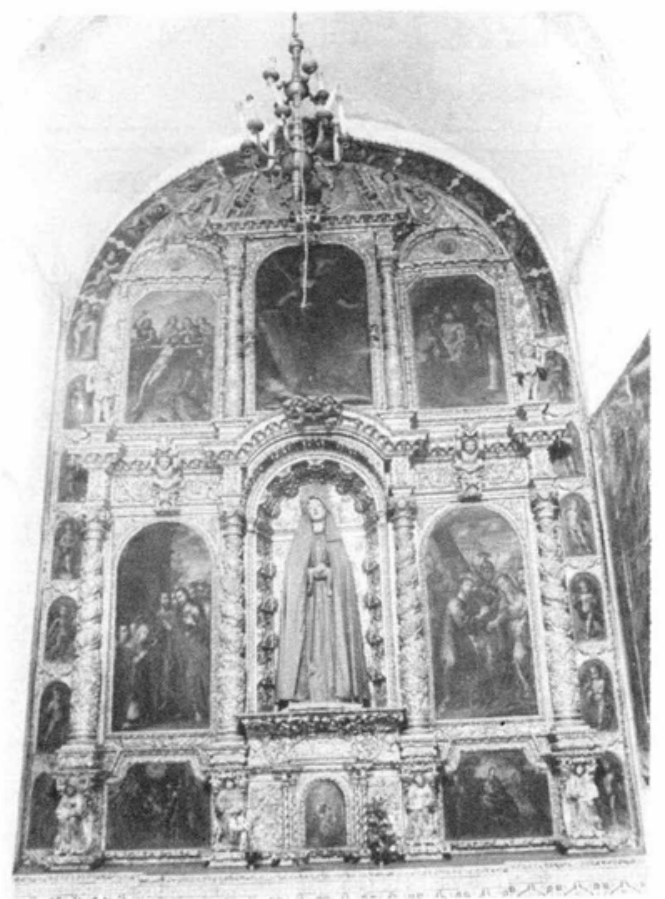
1. Retablo de la Virgen de los Dolores proveniente de la hacienda de Santa Lucía.

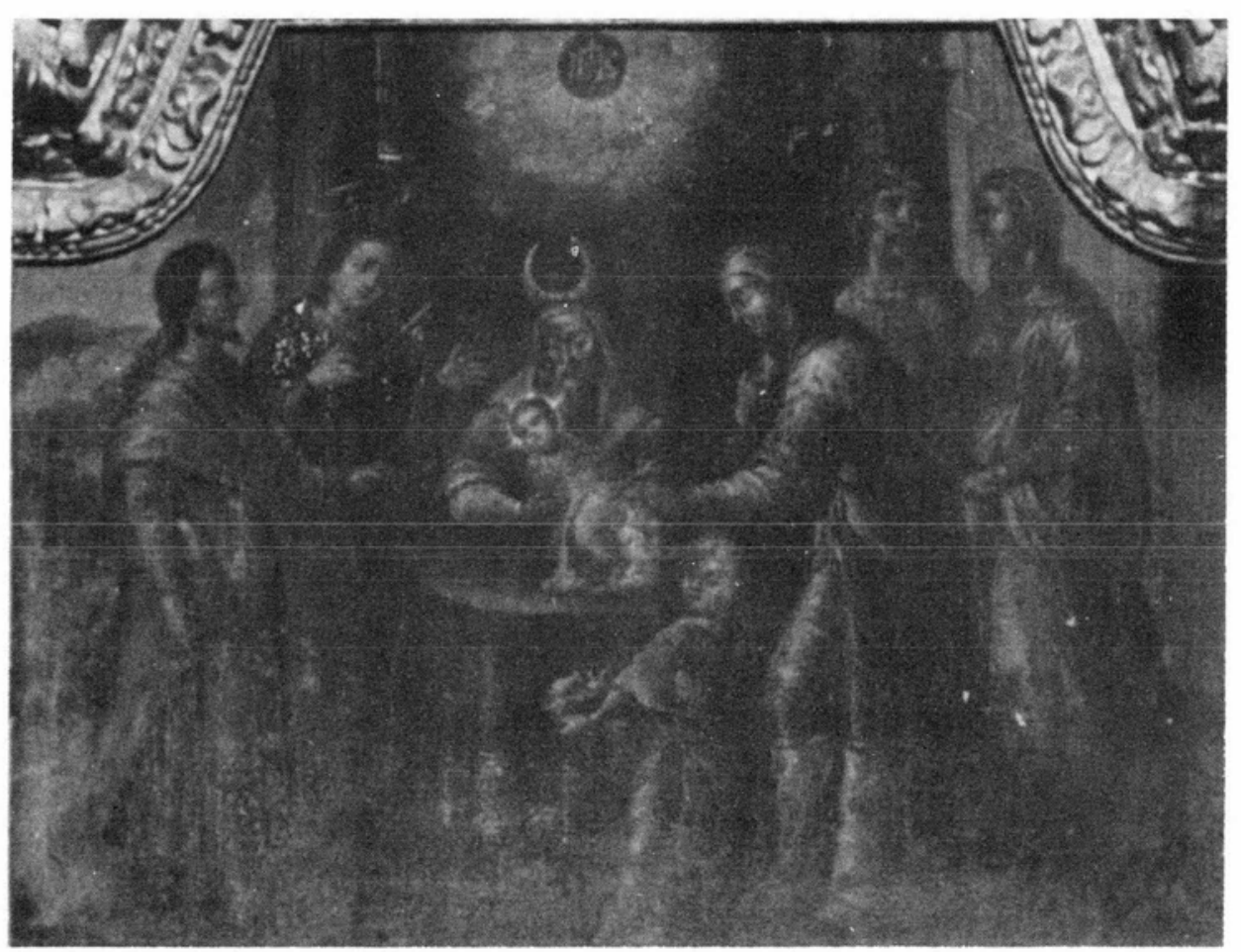

2. Anónimo, Presentación y Circuncisión del retablo de la Virgen de los Dolores. 


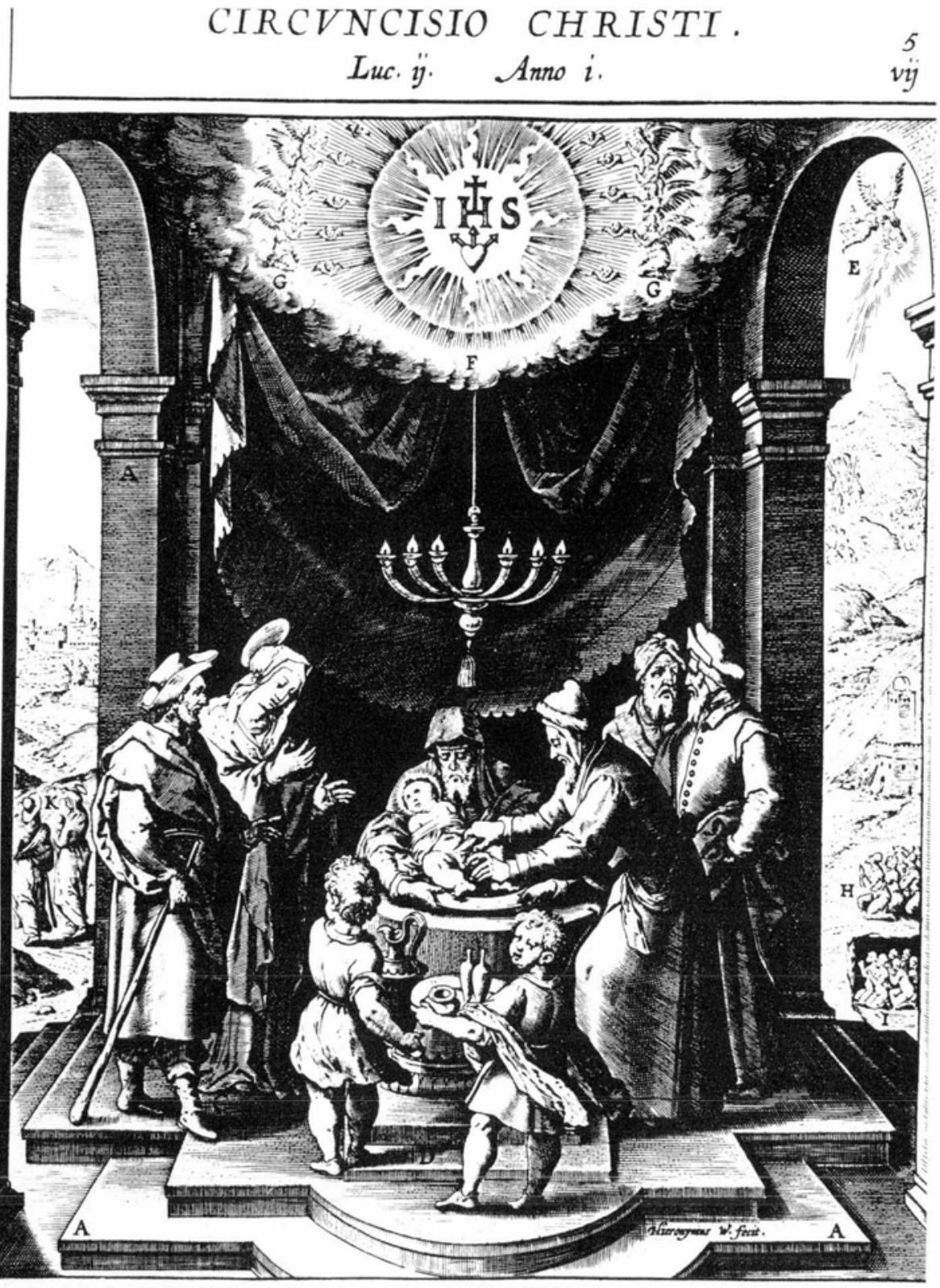

A. Synagoga, fue locus, vbi circunciditur IESVS.

B. Sacerdos cum carcmonits circuncifion's.

C. Virgo Mater dolet de vilnere filiy. Do: let Io epph.

D. Pueri fubferuientes.

E. Stella

demons trant.

F. Nomen IESV: quod adorant.

G. Angeli'.

H. Mortales.

I. Anima Patrum i limbo, حo qua in Purgatorio.

K. Maria finu fouens filum, redit cum Iofeph.

3. J. Wierix. Circuncisión. Grabado, ca. 1593. 
Casas ${ }^{19}$ Según esta fórmula, la Virgen de la Piedad se usa como símbolo de sus demás dolores, excluyendo toda representación de los otros episodios narrativos de su vida y de la del Niño Jesús. Es evidente que en este tipo de representación no se trata de una comparación adecuada con nuestra predela, ya que nuestro ciclo se funda en una tradición distinta, que consiste en representar los diferentes sucesos de la vida de la Virgen asociados con sus dolores.

Es entonces necesario que nos concentremos en otro tipo de retablo que trata de la Pasión y la vida de la Virgen. Observamos que en ningún ciclo de Correa sobre la vida de la Virgen se fusionó la Presentación con la Circuncisión y que, en general, se favorecía al primer episodio, excluyendo muchas veces una representación del segundo, como se puede ver en el ciclo de óleos de Correa para el convento de Santa Mónica de Puebla, hoy en el museo del mismo. ${ }^{14}$ José de Ibarra, cuyo maestro fue Juan Correa, seguía las tendencias de este último. Ibarra tiene un ciclo de ocho paneles dedicado a la Virgen en el que se incluye la Presentación, pero no la Circuncisión. ${ }^{15}$ De esta manera, pasando de maestro a aprendiz, se creó una tradición iconográfica en la Nueva España en la cual la Presentación se insertaba en ciclos dedicados a la vida de la Virgen con mayor frecuencia que la Circuncisión.

Enotro tipo de programas pictóricos dedicados no ala Virgen sinoa la vida del Niño Jesús, la Circuncisión sí aparece como tema independiente, pero siempre sin combinarse con el episodio de la Presentación. Por ejemplo, un contemporáneo de Correa, Juan Rodríguez Juárez, dedica en el claustro del ex convento de Tepotzotlán, México, una luneta a la Circuncisión y otra a la Presentación. ${ }^{16}$ Esta misma tendencia parece ser la que Miguel Cabrera hereda y practica en la siguiente generación. En la sacristía de Santa Prisca, en Taxco, su Circuncisión aparece junto a otra tela suya de la Presentación. ${ }^{17}$

Se puede concluir que bien sea la vida de la Virgen o la del Niño Jesús el tema central de un programa iconográfico, se representaba o un

${ }^{13}$ Elisa Vargaslugo, Juan Correa. su vida y su obra, Catálogo, México, Univer sidad Nacional Autónoma de México, 1985, ilustración núm. 205.

${ }^{14}$ Vargaslugo, op. cit., p. 99.

${ }^{15}$ Manuel Toussaint, Pintura colonial en México, México, Univer sidad Nacional Autónoma de México, 1965, ilustración núm. 298

${ }^{16}$ Agustín Velázquez Chávez, Tres siglos de pintura colonial mexicana, México, Editorial Polis, 1939, ilustración núm. 78. La Circuncisión de Juárez es interesante porque también parece haber tenido alguna influencia del grabado de Wierix, especialmente en su composición arquitectónica, la insignia IHS que mantiene en el centro superior, y en la figura del criadito. Un estudio más amplio podría empezar a recoger obras coloniales como ésta, que usaron los grabados de Nadal; de esta manera se descubriría el grado de su influencia en la pintura colonial.

${ }_{17}$ Abelardo Carrillo y Gariel, El pintor Miguel Cabrera, México, Instituto Nacional de Antropología e Historia, 196, ilustraciones núm. 68 y núm. 70. 
episodio u otro, en general la Presentación más que la Circuncisión; y en el caso en que se incluyeran los dos episodios, éstos se mostraban por separado. Hasta ahora no he encontrado otro caso en que las dos escenas, la de la Presentación y la de la Circuncisión, estén fusionadas en una sola tela, como se ve en nuestra predela. Tampoco se trata de insistir en que ésta sea un caso único. Si bien no se ha encontrado otro hecho paralelo en la colonia, es interesante que Louis Réau confirme que la iconografía de la Circuncisión corre el peligro de confundirse con la de la Presentación y que sostenga que, cuando la Circuncisión se dejaba de representar pictóricamente desde el siglo xviI, con frecuencia se combinaba con la Presentación. ${ }^{18}$ Réau apunta que la Circuncisión y la Presentación se han mostrado a veces de maneras no siempre bíblicamente fieles o al menos no litúrgicamente correctas. Nuestra predela de la Presentación-Circuncisión constituye un ejemplo de este caso y de este tipo de fusión al cual se refiere Réau.

Mientras no haya otros ejemplos coloniales de esta iconografía que combinen la Presentación con la Circuncisión en la colonia, nuestra obra se manifiesta como un caso poco común que requiere una explicación. Lo usual en el arte religioso era mantener la precisión dogmática y no romper con ella del modo como hace nuestra predela. La cuidadosa fidelidad al evangelio es una característica de la gran mayoría de las obras coloniales del siglo Xvil. De hecho, respecto al caso de Juan Correa, Elisa Vargaslugo comenta repetidamente que "se apegó fielmente a las Sagradas Escrituras" en sus obras. ${ }^{19} \mathrm{~A}$ veces, esta fidelidad se explica por un más estricto acatamiento de los decretos tridentinos en las colonias o mayor imposición de ellos. Es más, se suponía que fueron especialmente los jesuitas quienes diseminaron las ideas de Trento en las colonias, patrocinando una iconografía clara y simple basada en los textos del evangelio y supervisando la investigación de asuntos dudosos en el terreno de las artes. ${ }^{20} \mathrm{~A}$ primera vista, nuestra predela pareciera contrarrestar estas características de la pintura religiosa en la colonia, y es aún más sorprendente que tal cosa ocurra en un retablo jesuita. Por esto mismo, cabe preguntarse el porqué de la integración de dos escenas en una sola en el retablo jesuítico de Santa Lucía y el porqué de otorgar tanta importancia a la escena de la Circuncisión.

${ }^{18}$ Réau, op. cit., p. 258, 260.

${ }^{19}$ Vargaslugo, op, cit., p. 99

${ }^{20}$ Marco Díaz nos hace recordar que "... es una tesitura originada en el Concilio de Trento, donde se pide una devoción tierra a tierra que suscitó preocupaciones de los jesuitas en el terr eno de la iconografïa ..". Marco Díaz, La arquitectura de los jesuitas en Nueva España, México, Universidad Nacional Autónoma de México, 1982, p. 204. 
Al estudiar la tradición pictórica que representa la Circuncisión a fondo, notamos que el contexto jesuita de este retablo nos ayuda a explicar sus irregularidades. Aunque la Presentación constituye el primer dolor de la Virgen, el número de sus dolores, los acontecimientos que los determinan y su representación pictórica han ido variando a través de los siglos, y es precisamente en la historia artística de la Circuncisión donde ha habido una evolución significativa para nuestro estudio. Según Réau, en la Edad Media la Circuncisión se consideraba motivo de uno de los primeros dolores de la Virgen, pero posteriormente se la dejó de representar por que se consideraba como un hecho un tanto indecoroso para las artes. ${ }^{21}$ Sin embargo, Réau nos informa que, después de la Reforma y gracias al impulso de los jesuitas, la Circuncisión recobró popularidad en la representación pictórica. Para los jesuitas, la Circuncisión entrañaba especial importancia por coincidir el primero de enero con la imposición del nombre a Jesús, nombre que dio título a la Compañía. ${ }^{22}$

Las observaciones de Réau proporcionan un marco histórico estimado dentro del cual se puede analizar por qué se usó el grabado de Wierix en nuestra predela. Se puede así entender cómo el interés jesuita por la Circuncisión determinó estas decisiones artísticas a pesar de que la fusión con la Presentación reflejaba ciertas irregularidades teológicas.

Más aún, si se tiene en cuenta el fervor con el cual las comunidades religiosas, especialmente las de jesuitas, practicaban el culto de la Dolorosa, ${ }^{23}$ es posible que el pintor del retablo, o más bien el padre jesuita de Santa Lucía que lo encomendó, considerara que la escena de la Circuncisión ofrecería un momento más dramático y expresaría mejor la sintonía de María con los dolores de su Hijo, que la mera escena de la Presentación. Traducido al plano pictórico, el motivo evangélico de la Presentación no transmite el dolor de María con la misma intensidad que el de la Circuncisión. En nuestro retablo se le inflige al Niño un dolor físico y real al cual la Virgen responde dolorida. En efecto, su reacción ante el dolor del hijo, esa especie de conversación silenciosa entre ambos, se detecta como núcleo de todos los óleos del retablo. ${ }^{24}$ Esta hipótesis se adhiere a lo expresado por

${ }^{21}$ Réau, op. cit., pp. 258-259

${ }^{22}$ Ibid, p. 258

${ }^{23}$ Tanto Bargellini como Curiel sugier en que el culto a la Dolorosa estaba creciendo en la Nueva España cuando se realizó este retablo. Ambos subrayan que fueron los jesuitas quienes en gran parte apoyaron la propagación del culto a la Virgen de los Dolores.

${ }^{24}$ Esta observación se tendría que investigar con mayor detalle en un estudio que, teniendo en cuenta la influencia de los jesuitas y el tipo de iconografía que desearon en el ambiente de una hacienda, abarcara el retablo en su totalidad, su iconografía y su estilo pictórico 
Díaz sobre las obras jesuíticas de la Nueva España: “...los mensajes... parecen estar más conducidos por razones piadosas queteológicas" ${ }^{25} \mathrm{El}$ énfasis en representar primordialmente la Circuncisión obedecería a la idea de que los jesuitas buscaban en Santa Lucía un arte emotivo, un tema que realzara el dolor de la Virgen de una manera literal. Más que sabida es la importancia que San Ignacio de Loyola, y en consecuencia la Compañía, daba a la participación de los sentidos en la devoción. ${ }^{26}$

En consecuencia, es posible que esta irregularidad en la predela del retablo de Santa Lucía que rompe con la cronología de los sucesos evangélicos se pueda explicar por el esfuerzo de combinar armoniosamente la siempre requerida Presentación con la Circuncisión, porque ésta segunda inspiraba mayores sentimientos de emoción en los devotos y a la vez tenía una significación conmemorativa y simbólica para una comunidad jesuítica. A la vez, en ningún retablo dedicado a la Virgen de los Dolores podía faltar la Presentación, ya que ésta, como antes se dijo, constituye la justificación bíblica de esa devoción mariana. Además, la tradición pictórica recalcaba su papel como el primer dolor de la Virgen. ${ }^{27}$

En vista de que se desconoce el contrato de este retablo, no se puede precisar con exactitud el papel que tuvieron los jesuitas en la elección del grabado de Wierix como modelo para la predela. Sin embargo, es muy probable que los jesuitas hayan determinado su programa pictórico y hayan decidido combinar la Circuncisión con la Presentación entre los dolores de la Virgen. En cuanto al grabado en sí, cabe la posibilidad de que se encontrara suelto en el taller del pintor del retablo y que fuera éste quien decidiera inspirarse en él. Es consabido que los pintores coloniales solían guardar carpetas enteras de grabados provenientes de maestros europeos para usarlos como modelos de sus propias obras. ${ }^{28}$ Sabemos también qué estampas sueltas de las Imágenes formaban un mercado independiente. ${ }^{29}$

\footnotetext{
${ }^{25}$ Díaz, op cit, p. 204

${ }_{26}^{26}$ Para un resumen de estas ideas véase Rodríguez de Ceballos, op. cit., p. 7. El mismo nos dice que "... hay un punto en que casi todos los críticos coinciden: la utilización de la imagen visual por parte de los jesuitas como instrumento de captación personal a través de los sentidos".

${ }^{27}$ Según Trens, quien identificó los cinco grupos de siete dolores que se representaban con mayor frecuencia, en el siglo xvi prevalecía el grupo que empieza con la Profecía de Simeón, o sea la Presentación. Manuel Trens, Maria iconografía de la Virgen en el arte español, Madrid, Editorial Plus-Ultra, 1946, 225.

${ }^{28}$ Como Jorge Alberto Manrique ha indicado, un solo retablo podía ser el resultado de la fusión de varios grabados de distintos orígenes. Jorge Alber to Manrique, "La estampa como fuente del arte en la Nueva España", op cit, p. 59

${ }^{29}$ Algunos grabados sueltos de la obra de Nadal llegaron incluso hasta Japón y China Rodríguez de Ceballos, op cit., p. 14.
} 
Ya fuera decisión de la Compañía o tan sólo del pintor usar este grabado como fuente de inspiración en Santa Lucía, tenemos aquí una muestra más de que tanto en España como en la Nueva España las Imágenes de Nadal no sólo desempeñaron un papel importante para instruir al pueblo en el evangelio, sino que también sirvieron como modelo artístico. En este estudio se ofrece una posible interpretación para un problema iconográfico en relación con su contexto jesuítico. Ayuda a entrever el gran papel que debió de jugar la Compañía de Jesús en la Nueva España como mecenas en el siglo xviı.

\section{BIBLIOGRAFÍA}

Bargellini, Clara: "Lower Portion of a Retablo", Mexico: Splendors of Thirty Centuries, New York, Metropolitan Museum of Art, 1990.

Burke, Marcus: "Print Sources in Mexican Painting", Spain and New Spain. Colonial Arts in their European Context, Art Museum of South Texas, Texas, 1979.

Carrillo y Gariel, Abelardo: El pintor Miguel Cabrera, México, Instituto Nacional de Antropología e Historia, 1966.

Curiel, Gustavo: "Las pinturas de Nuestra Señora de los Dolores y Nuestra Señora de la Piedad en la obra de Juan Correa", Juan Correa su vida y su obra, vol. 1 (en prensa).

Díaz, Marco: La arquitectura de los jesuitas en Nueva España, México, Universidad Nacional Autónoma de México, 1982.

Manrique, Jorge Alberto: "La estampa como fuente del arte en la Nueva España", Anales, núm. 50, 1982.

Réau, Louis: Iconographie de l'art chrétien, vol. 2, Paris, Presses Universitaires de France, 1957.

Rodríguez G. đe Cebalios: "Las imágenes de la historia evangélica del P. Jerónimo Nadal en el marco del jesuitismo y la contrarreforma", Imágenes de la historia evangélica (1593), Barcelona, El Albir, 1975.

Toussaint, Manuel: Pintura colonial en México, México, Universidad Nacional Autónoma de México, 1965.

Trens, Manuel: Maria. iconografia de la Virgen en el arte español, Madrid, Editorial PlusUltra, 1946.

Vargaslugo, Elisa: Juan Correa; su vida y su obra, México, Universidad Nacional Autónoma de México, 1985.

Velázquez Chávez, Agustín: Tres siglos de pintura colonial mexicana, México, Editorial Polis, 1939. 